\title{
Avulsion of the right main stem bronchus associated to a false aneurysm of the right subclavian artery after closed chest trauma
}

\author{
J P BARROY, ${ }^{1} \mathrm{M}$ GELIN, ${ }^{1} \mathrm{M}$ VAN STRATUM, ${ }^{1} \mathrm{~J}$ P DEREUME, ${ }^{1}$ AND \\ P VANDERHOEFT ${ }^{2}$
}

From the Vascular Surgery Department and Department of Surgery, ${ }^{1}$ and the Thoracic Surgery Service, ${ }^{2}$ Hôpital Erasme, Université Libre de Bruxelles, Bruxelles, Belgium

There are many published cases of tracheobronchial lesions or of vascular lesions in closed trauma but few with a combination of both types (Couraud et al, 1970; Hallen et al, 1974). In either situation recognition of the lesions is of ten delayed. Our case concerns a car driver in whom both lesions coincided: a bronchial avulsion confirmed on the second day and an arterial false aneurysm diagnosed on the 21 st day.

\section{Case report}

A 23-year-old car driver, wearing a diagonal and lap strap safety belt, crashed into a concrete wall. He presented with a right pneumothorax and mediastinal emphysema, rib fractures on the right, a fractured left clavicle, and tracheal bleeding. His trachea was intubated and the pneumothorax was drained. He was transferred to our hospital the next day with a bilateral pneumothorax. At the time of bilateral pleural drainage, a bronchoscopy showed a rupture of the right main bronchus. Emergency thoracotomy disclosed a total avulsion with a one centimetre gap flush with the trachea. The right lung could be ventilated because the peribronchial tissues were intact. The only other lesion discovered was a laceration of the right lower lobe. Direct anastomosis of the right main bronchus was performed with interrupted sutures. Bilateral atelectasis necessitated mechanical ventilation for nine days.

A bronchogram on the 20th day was normal (fig 1). From the time of admission a continuous murmur had been noted under the right clavicle. The systemic blood pressure was found to be $100 / 50 \mathrm{mmHg}$ in the right arm and $140 / 70 \mathrm{mmHg}$ in the left. Arteriography showed a right subclavian aneurysm with diminished flow through it and an absent right vertebral artery (fig 2).

One month after the accident, through a median sternotomy, the subclavian artery was clamped above and below the aneurysm, which was opened and bypassed with a venous graft. The graft thrombosed but patency was restored six hours later with a Fogarty catheter. The radial artery blood pressure returned to $140 / 70 \mathrm{mmHg}$. The patient went home 40 days after his accident.

In the third month bronchoscopy disclosed slight stenosis at the suture line. At six months a broncho-

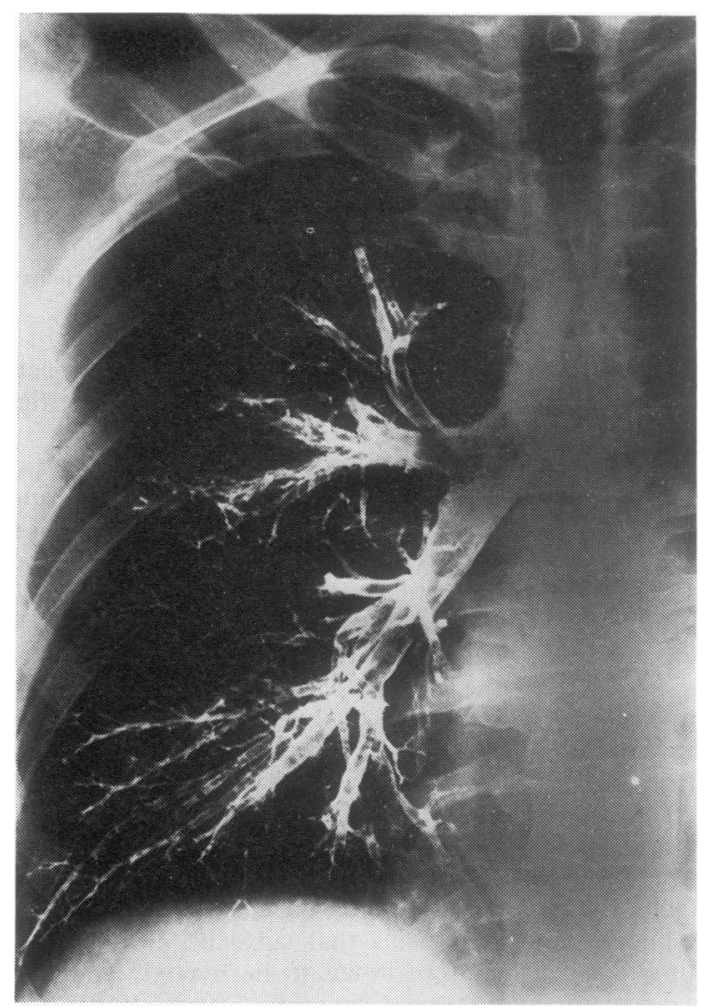

Fig 1 Bronchogram 20 days after repair of right main bronchus.

gram showed a moderate stenosis, but respiratory function tests, including a ${ }^{133} \mathrm{Xe}$ lung scintigram, were normal. The patient resumed his professional work in the seventh month and is leading a normal life two years later.

\section{Discussion}

The mechanism of this triple lesion is directly related to the double strap safety belt. The left clavicle broke $\mathbb{\Phi}$ under pressure from the left shoulder strap. The latter, with the lap strap, let the right shoulder and hemi- 


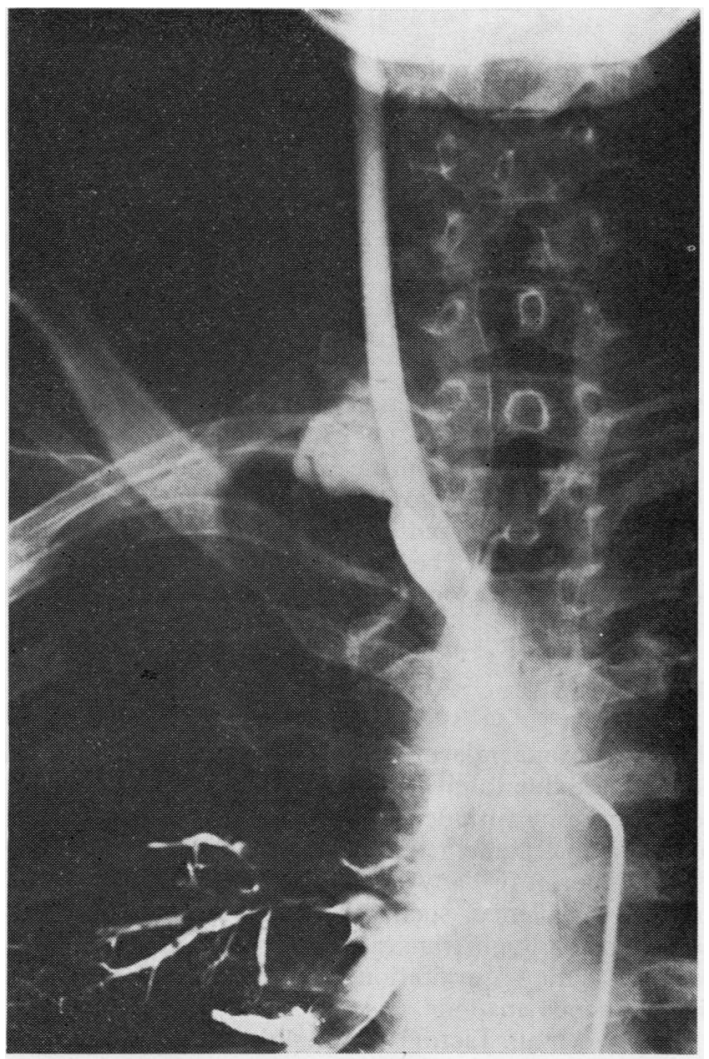

Fig 2 Arteriogram showing false aneurysm of right subclavian artery.

thorax free, but as there were no signs of contusion on the right shoulder it is unlikely that it hit anything. The slower vertical deceleration of the right hemi- thorax, compared to the rest of the body, then tore the right bronchus and subclavian artery flush with their connexions - the trachea and the innominate artery.

All authors insist on the necessity of bronchoscopy in thoracic trauma followed by pneumothorax and haemoptysis: it is the only investigation that can locate the bronchial lesion. As to the vascular lesions, their diagnosis is often delayed. Sternotomy is the recommended approach as this allows good control of the large vessels (Murray, 1971; Gunnlaugsson et al, 1973; Rich et al, 1973). In retrospect, if both lesions had been recognised before our patient was operated on, they could have both been repaired through a median sternotomy.

\section{References}

Couraud, L, Amar, A, and Bruneteau, A (1970). Les ruptures trachéales et bronchiques post-traumatiques. La Presse Médicale, 78, 1823-1826.

Gunnlaugsson, G H, Hallgrimsson, J C, Sigurdsson, J L, Cleland, W P, and Mearns, A J (1973). Complete traumatic avulsion of the innominate artery from the aortic arch with a unique mechanism of injury. Journal of Thoracic and Cardiovascular Surgery, 66, 235-240.

Hallen, A, Hansson, H E, and Nordlund, S (1974). Thoracic injuries. A survey of 765 patients treated during 1956-1969. Scandinavian Journal of Thoracic and Cardiovascular Surgery, 8, 3445.

Murray, J F (1971). A case of total rupture of the right main bronchus after closed chest injury. British Journal of Anaesthesia, 43, 407-408.

Rich, N M, Hobson, R W, Jarstfer, B S, and Geer, T M (1973). Subclavian artery trauma. Journal of Trauma, 13, 485-496.

Requests for reprints to: Dr J P Barroy, Service de chirurgie, Hôpital Saint-Pierre, Rue Haute, 322, B 1000 Bruxelles. 